www.jmscr.igmpublication.org

Impact Factor (SJIF): 6.379

Index Copernicus Value: 71.58

ISSN (e)-2347-176x ISSN (p) 2455-0450

crossref DOI:_https://dx.doi.org/10.18535/jmscr/v6i4.07

Journal Of Medical Science And Clinical Research

\title{
Comparison of two Different Low Doses of Intrathecal Bupivacaine \& Fentanyl Mixture in Caesarean Section \& to see the Relevance of Preloading in Them
}

\author{
Authors \\ Deepika Meena', Sonali Dhawan ${ }^{2}$, Pramila Soni ${ }^{3}$, Rashmi Jain ${ }^{4}$, Peeru Singh ${ }^{5}$ \\ Priyanka Dixit ${ }^{6}$ \\ ${ }^{1}$ Resident, ${ }^{2}$ Professor, ${ }^{3}$ Assistant Professor, ${ }^{4}$ Senior Resident, ${ }^{5}$ Assistant Professor, ${ }^{6}$ Resident \\ Department of Anaesthesia, Sardar Patel Medical College \& AGH, Bikaner, Rajasthan \\ Corresponding Author \\ Deepika Meena
}

Resident, Department of Anaesthesia, Sardar Patel Medical College \& AGH, Bikaner, Rajasthan Email: deepika4289@gmail.com

\begin{abstract}
Background and Aim: Pregnant woman are more sensitive to local anaesthetics during caesarean section. The aim of this prospective, double blind randomized controlled study was to compare two different low doses of intrathecal bupivacaine \& fentanyl mixture in caesarean section and to see relevance of preloading in them to maintain stable hemodynamics and provide better analgesia with minimal complications.
\end{abstract}

Materials and Method: 200 parturient scheduled for caesarean section were randomly allocated into 2 groups of 100 patients each and a subgroup of 50 patients. Group1A (0.5\% Hyperbaric Bupivacaine $7.5 \mathrm{mg}+25 \mu \mathrm{g}$ fentanyl with preloading colloid $10 \mathrm{ml} / \mathrm{kg})$, GrouplB $(0.5 \%$ Hyperbaric Bupivacaine $7.5 \mathrm{mg}+25 \mu \mathrm{g}$ fentanyl without preloading), Group $2 \mathrm{~A}$ (0.5\% Hyperbaric Bupivacaine $5 \mathrm{mg}+25 \mu \mathrm{g}$ fentanyl $+0.5 \mathrm{ml} \mathrm{NS}$ with preloading colloid $10 \mathrm{ml} / \mathrm{kg})$ and Group $2 B(0.5 \%$ Hyperbaric Bupivacaine $5 \mathrm{mg}+25 \mu \mathrm{g}$ fentanyl $+0.5 \mathrm{ml}$ NS without preloading).Maternal hemodynamics, duration of sensory and motor analgesia, total duration of analgesia and apgar score of the new born were compared between the groups and analysed by SPSS software using anova and student t test.

Result: Hemodynamic status was more stable in group-2 with less significant fall in mean blood pressure. Surgical anaesthesia was of equal quality in both and apgar score was $\geq 9$ in both the groups. Total duration of analgesia in group $1 A$ was $182.64 \pm 11.45$, group $1 B$ was $180.42 \pm 12.93$, group $2 A$ was $154.04 \pm 10.56$ and group $2 B$ was 156.02 \pm 9.43 . So, the total duration of analgesia which was assessed by VAS was excellent in the group 1.

Conclusion: As we are taking caesarean section in our study which takes maximum upto 40-50 min. So the combination of diluted low-dose bupivacaine and fentanyl could provide more stable hemodynamic status, without compromising required surgical anaesthesia and minimum complications to mother with no foetal compromise.

Keywords: Spinal-anaesthesia, local-anaesthetic, fentanyl, caesarean-section. 


\section{Introduction}

Obstetric anaesthetists face with the unique situation of providing anaesthesia for caesarean sections, where anaesthetists have to provide care for both the mother and the unborn baby. There has an increasing trend in the caesarean section rate in the last two decades not just in developed countries but also in developing countries. ${ }^{1}$ Pregnancy as well as labour and delivery are accompanied by physiological changes in multiple organ systems that may influence maternal responses to anaesthesia and choice of anaesthetic technique. ${ }^{2}$ Regional anaesthesia has become most preferred technique for caesarean section. Spinal anaesthesia has a more rapid, predictable onset , produce a more dense (complete) block and lacks the potential for serious systemic drug toxicity because of the smaller dose of local anaesthetic employed. ${ }^{3}$ Pregnant woman are more sensitive to local anaesthetics. The same level of spinal blockade is achieved with a smaller dose of local anaesthetic compared with that in non-pregnant individual. ${ }^{4}$

The chance of hypotension is a major limitation of regional anaesthesia. The incidence of hypotension is more than $80 \%$ without any prophylactic measures. ${ }^{5,6}$ The hypotension with or without bradycardia has detrimental effects on both mother and foetus. ${ }^{7,8}$

Measures that decrease the incidence of hypotension to varying degree includes intravenous administration of fluids whether preloading or coloading, avoidance of aortocaval compression, lowering the dose of anaesthetic agent and monitoring of blood pressure at frequent intervals after placement of regional anaesthesia. Although matter of preloading has been controversial from years that whether it is beneficial to avoid hypotension or not.

Among the local anaesthetics hyperbaric bupivacaine is the preferred local anaesthetic. The unique characteristic of this drug is the highest potency, slow onset of action and longer duration. With the combination of local anaesthetics and opioids, dose is decreased which is beneficial in obstetrics anaesthesia as we can avoid toxicity due to large doses, hypotension ,nausea, vomiting and other side effects for which pregnant patients are more prone.

\section{Materials and Method}

This study was conducted on 200 cases in the Department of Anaesthesiology, Sardar Patel Medical College and Associated Group of Hospitals Bikaner and the study design was approved by hospital ethical committee prior to data collection and written informed consent was taken from all patients. Patients posted for caesarean section ranging between the age group 18 to 30 years of height 150 to $170 \mathrm{~cm}$ belonging to ASA I or II grades, undergoing elective lower segment caesarean section under subarachnoid block were included in study. They were randomized into 2 groups of 100 patients each and a subgroup of 50 patients each.

\begin{tabular}{|l|l|}
\hline Group 1A & $\begin{array}{l}0.5 \% \text { Hyperbaric Bupivacaine } 7.5 \mathrm{mg}+ \\
25 \mu \mathrm{g} \text { fentanyl with preloading colloid } \\
10 \mathrm{ml} / \mathrm{kg}\end{array}$ \\
\hline Group 1B & $\begin{array}{l}0.5 \% \text { Hyperbaric Bupivacaine } 7.5 \mathrm{mg}+ \\
25 \mu \mathrm{g} \text { fentanyl + without preloading }\end{array}$ \\
\hline Group 2A & $\begin{array}{l}0.5 \% \text { Hyperbaric Bupivacaine } 5 \mathrm{mg}+25 \mu \mathrm{g} \\
\text { fentanyl }+0.5 \mathrm{ml} \text { NS with preloading colloid } \\
10 \mathrm{ml} / \mathrm{kg}\end{array}$ \\
\hline Group 2B & $\begin{array}{l}0.5 \% \text { Hyperbaric Bupivacaine } 5 \mathrm{mg}+25 \mu \mathrm{g} \\
\text { fentanyl+0.5ml NS without preloading }\end{array}$ \\
\hline
\end{tabular}

\section{Inclusion Criteria}

1. Patients scheduled for elective caesarean section with uncomplicated pregnancy were included in the study.

2. ASA (American society of anesthesiology) grade 1 and 2 .

3. Height $150-170 \mathrm{~cm}$

4. Age 18-30 years.

\section{Exclusion Criteria}

1. Parturient having pre-eclampsia, eclampsia, placenta previa

2. Weight $>90 \mathrm{~kg}$

3. Height $<150 \mathrm{~cm}$ or $>165 \mathrm{~cm}$

4. Any contra-indication to regional anaesthesia .

5. History of drug hypersensitivity to Local anaesthetic agent. 
6. ASA grade 3 and 4

7. Any major systemic illness, fetal compromise.

8. Active disease of CNS such as meningitis, polio myelitis, intracranial haemorrhage, sub acute combined degeneration of spinal cord.

9. Spinal stenosis and active disease (spondylitis, TB, tumours).

10. Spinal deformities.

11. Septicemia.

12. Cardiogenic or hypovolemic shock .

13. Coagulation disorders .

14. Severe Anaemia .

Preoperative assessment was done for each patient, procedure of spinal anaesthesia was explained and written informed consent was taken from the patient and her relatives. Intravenous line was obtained with $18 / 20$ guage cannula and group 1A and 2A were preloaded with colloid $500 \mathrm{ml}$ half an hour before anaesthesia. All patients received Inj. Rantidine 50mg IV and Inj. Metoclopramide 10mg IV for aspiration prophylaxis before surgery. Routine laboratory investigations was done (Haemogram, Bleeding time, Clotting time, blood group, viral markers, Urine albumin/sugar). Before proceeding with the spinal anaesthesia boyle,s anaesthesia machine was checked, appropriate sized endotracheal tubes, working laryngoscope, a working suction apparatus and emergency drugs along with mephentermine and atropine were kept ready.

Standard monitoring was applied with noninvasive $\mathrm{BP}, \mathrm{HR}, \mathrm{PR}, \mathrm{SpO}_{2}$. Pre-anaesthetic values of heart rate, mean arterial pressure, $\mathrm{O}_{2}$ saturation and pulse oximetry were recorded. Under aseptic conditions the subarachnoid space puncture was performed using $25 \mathrm{G}$ quincke's spinal needle between the $\mathrm{L}_{3}-\mathrm{L}_{4}$ space and group 1 recieved $7.5 \mathrm{mg}$ of hyperbaric $0.5 \%$ bupivacaine plus Fentanyl $25 \mathrm{mcg}$ after confirming free back flow of cerebrospinal fluid in the needle. Similarly group 2 received $5 \mathrm{mg}$ of hyperbaric $0.5 \%$ bupivacaine plus fentanyl $25 \mathrm{mcg}$ plus $0.5 \mathrm{ml}$ sterile normal saline.
Afterwards patient was placed in the supine position with a 15 degree head down position. The wedge was placed under patients right buttock to avoid the supine hypotention syndrome. Oxygen was supplemented by using ventimask.

\section{Intraoperative Monitoring}

Continuous monitoring of haemodynamic parameters (Pulse, systolic and diastolic BP, SPO2) were recorded every $2 \mathrm{~min}$ for first $10 \mathrm{mins}$ and thereafter for every $5 \mathrm{~min}$ intraoperatively. Intraoperative side effects like pain, headache, nausea, vomiting, pruritus, shivering etc were noted.

The following parameters were observed and recorded.

\section{A. Sensory Block}

1. Onset of sensory blockade.

2. Maximum level of sensory blockade attained.

Sensory level of the block was assessed by loss of sensation bilaterally at $30 \mathrm{sec}$ intervals and confirmed by a pin prick method.

\section{B. Motor Block}

3. Maximum motor blockade attained and the time taken for the same

4. Quality/ degree of motor blockade was assessed by modified Bromage scale.

\section{Modified bromage scale}

1. Free movement of legs and feet.

2. Just able to flex knees with free movement of feet.

3. Unable to flex knees but free movement of feet.

4. Unable to move legs and feet.

\section{Haemodynamic Parameters}

5. Haemodynamic parameters (systolic $\mathrm{BP}$, diastolic $\mathrm{BP}$, mean $\mathrm{BP}$, pulse, $\mathrm{spo}_{2}$ ) were recorded. A decrease of systolic bp $<90 \mathrm{~mm}$ of hg or decrease $>20 \%$ from baseline was considered 
hypotension and treated with 3-5mg of mephentermine.

6. Total duration of analgesia was noted using visual analog scale.

An intraoperative and postoperative pain assessment was done using visual analog scale(VAS)

Duration of effective analgesia was taken from the time of intrathecal injection to a vas score $\geq 4$

\section{Visual Analog Scale}

VAS is a $10 \mathrm{~cm}$ horizontal line labelled as no pain at one end and worst pain imaginable on the other end. Patient was asked to mark on the line where the pain lies.

$\begin{array}{ll}0 & \text { No pain } \\ 1-3 & \text { Mild pain } \\ 4-6 & \text { Moderate pain } \\ 7-10 & \text { Severe pain }\end{array}$

\section{E. Apgar Score}

7. Neonatal APGAR scores at 1 and 5 minutes interval were noted.

\section{Observations \& Results}

Mean age of patients were 24.74 \pm 3.12 , $24.70 \pm 2.71,24.50 \pm 2.97$ and $24.96 \pm 2.88$ in group $1 \mathrm{~A}$, group $1 \mathrm{~B}$, group $2 \mathrm{~A}$, group $2 \mathrm{~B}$ respectively and the differences were statistically insignificant in between all 4 groups with CD value $1.40 \%$. Mean height of patients were 159.12 \pm 3.81 , $159.92 \pm 3.03,159.9 \pm 2.93$ and $159.18 \pm 3.9$ in group $1 \mathrm{~A}$, group 1B, group $2 \mathrm{~A}$ and group $2 \mathrm{~B}$ respectively and the differences was statistically insignificant with $C D$ value 1.52. Mean weight of patients were $62.94 \pm 4.38,63.30 \pm 4.43,63.00 \pm 4.51$ and $62.0 \pm 4.4$ in group 1A, group $1 \mathrm{~B}$, group $2 \mathrm{~A}$ and group $2 \mathrm{~B}$ respectively and the differences were statistically insignificant with $\mathrm{CD}$ value 1.77 as shown in Table 1.

We observed that heart rate decreased from baseline in all four groups after 4 minutes but the difference was statistically insignificant at different time intervals.
There was fall in mean BP in all groups with greater fall in $\mathrm{BP}$ in group $1 \mathrm{~A}$ and $1 \mathrm{~B}$.On comparing group $1 \mathrm{~A}$ with group $1 \mathrm{~B}$ the difference was statistically insignificant at different time intervals. On comparing group 1A with group 2A and $2 \mathrm{~B}$ the difference was statistically significant at 4 and 6 minutes with $\mathrm{CD}$ value $2.67 \%$ and $3.72 \%$ respectively. On comparing group $1 \mathrm{~B}$ with group 2A and 2B the difference was statistically significant at 4 minutes with $\mathrm{CD}$ value $2.67 \%$. On comparing group 2A with group 2B the difference was insignificant at different time intervals as shown in Table 2.

Time of onset of sensory analgesia between all four groups and it was faster in group $1 \mathrm{~A}$ and group $1 \mathrm{~B}$ as compared to group $2 \mathrm{~A}$ and $2 \mathrm{~B}$ but the difference was statistically insignificant in all four groups with CD value $0.137 \%$ as shown in table 3 . Time of onset of motor block between all four groups and it was faster in group $1 \mathrm{~A}$ and group $1 \mathrm{~B}$ as compared to group $2 \mathrm{~A}$ and $2 \mathrm{~B}$ but the difference was statistically insignificant in all four groups with CD value $0.150 \%$ as shown in table 3 . Quality of motor block between all four groups and the difference was statistically insignificant in all four groups.

On comparing total duration of analgesia group $1 \mathrm{~A}$ with group $1 \mathrm{~B}$ the difference was statistically insignificant. On comparing group 1A with group $2 \mathrm{~A}$ and $2 \mathrm{~B}$ the difference was statistically significant with $\mathrm{CD}$ value $4.405 \%$. On comparing group $1 \mathrm{~B}$ with group $2 \mathrm{~A}$ and $2 \mathrm{~B}$ the difference was statistically significant with $\mathrm{CD}$ value $4.405 \%$. On comparing group $2 \mathrm{~A}$ with $2 \mathrm{~B}$ the difference was statistically insignificant. Apgar score was statistically insignificant in all four groups with CD value $0.201 \%$.

None of the patient complained of pruritus . Only 4 patients in group 1 complained of nausea and 6 patients complained of nausea and vomiting in group 1 while only 1 patient in group 2 complained of nausea and 1 patient suffered nausea and vomiting may be due to reduction of dose of bupivacaine causing less hypotension in group 2. Only 2 patients suffered pain during 
stretching in group $2 \mathrm{~A}$ and 3 in group $2 \mathrm{~B}$. Negligible incidences of shivering or respiratory depression was observed in both the groups. So, the proportion of adverse effects in intraoperative and early postoperative period, including nausea, vomiting, pain during stretching, shivering, pruritus etc were insignificant in all groups.

Table 1: Demographic characteristics

\begin{tabular}{|l|c|c|c|c|c|}
\hline Age & 1A & 1B & 2A & 2B & $\begin{array}{c}\text { CD5 } \\
\text { \% }\end{array}$ \\
\hline Mean \pm & 24.74 & 24.70 & 24.50 & 24.96 & 1.40 \\
SD & \pm 3.12 & \pm 2.71 & \pm 2.97 & \pm 2.88 & \\
\hline Ht(in & 159.1 & 159.9 & 159.9 & 159.1 & 1.52 \\
cm) & \pm 3.81 & \pm 3.03 & \pm 2.93 & \pm 3.9 & \\
\hline Wt(in & 62.94 & 63.30 & 63.00 & 62.00 & 4.51 \\
kg) & \pm 4.38 & \pm 4.43 & \pm 4.51 & \pm 4.4 & \\
\hline
\end{tabular}

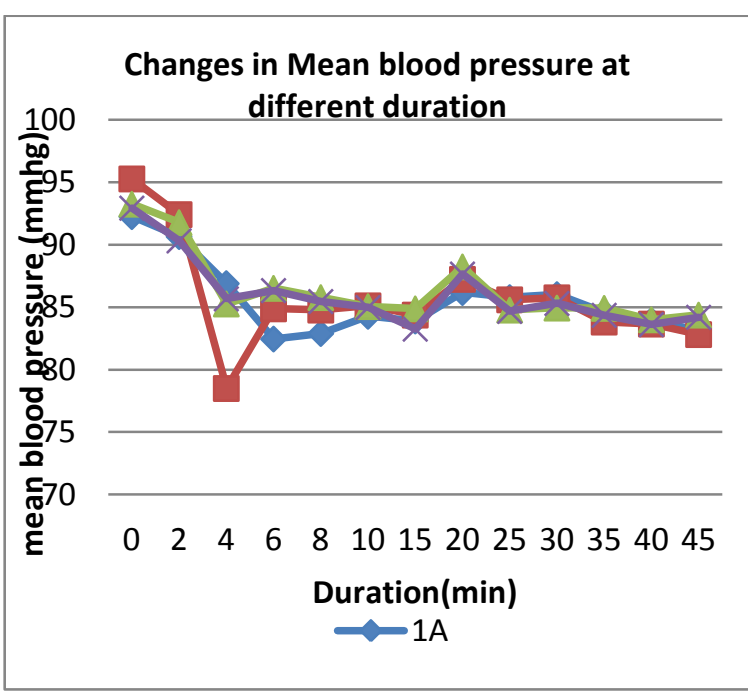

Table 2: Mean Blood Pressure at different time intervals.

\begin{tabular}{|l|c|c|c|c|c|}
\hline $\begin{array}{l}\text { Duration } \\
\text { (min) }\end{array}$ & G1 & G2 & G3 & G4 & $\begin{array}{c}\text { CD } \\
\mathbf{5 \%})\end{array}$ \\
\hline $\mathbf{0}$ & $92.26 \pm$ & $95.28 \pm$ & $93.26 \pm$ & $92.94 \pm$ & 3.56 \\
& 8.34 & 8.52 & 8.03 & 8.77 & \\
\hline $\mathbf{2}$ & $90.66 \pm$ & $92.42 \pm$ & $91.78 \pm$ & $90.32 \pm$ & 3.27 \\
& 8.18 & 8.23 & 7.61 & 6.83 & \\
\hline $\mathbf{4}$ & $79.90 \pm$ & $77.20 \pm$ & $80.57 \pm$ & $82.90 \pm$ & 2.67 \\
& 7.26 & 6.42 & 5.56 & 5.64 & \\
\hline $\mathbf{6}$ & $82.46 \pm$ & $84.88 \pm$ & $86.52 \pm$ & $86.34 \pm$ & 3.72 \\
& 9.41 & 9.65 & 8.12 & 6.84 & \\
\hline $\mathbf{8}$ & $82.90 \pm$ & $84.78 \pm$ & $85.78 \pm$ & $85.46 \pm$ & 3.18 \\
& 7.83 & 8.01 & 7.21 & 5.87 & \\
\hline $\mathbf{1 0}$ & $84.28 \pm$ & $85.12 \pm$ & $85.06 \pm$ & $84.98 \pm$ & 2.54 \\
& 5.94 & 6.58 & 5.95 & 4.95 & \\
\hline $\mathbf{1 5}$ & $83.90 \pm$ & $84.38 \pm$ & $84.88 \pm$ & $83.26 \pm$ & 2.43 \\
& 5.91 & 5.59 & 6.08 & 5.66 & \\
\hline $\mathbf{2 0}$ & $86.18 \pm$ & $87.24 \pm$ & $88.24 \pm$ & $87.66 \pm$ & 3.14 \\
& 7.83 & 8.24 & 6.78 & 6.00 & \\
\hline $\mathbf{2 5}$ & $85.78 \pm$ & $85.60 \pm$ & $84.78 \pm$ & $84.68 \pm$ & 2.70 \\
& 7.24 & 6.62 & 5.77 & 5.68 & \\
\hline
\end{tabular}

\begin{tabular}{|l|c|c|c|c|c|}
\hline $\mathbf{3 0}$ & $86.02 \pm$ & $85.76 \pm$ & $84.94 \pm$ & $85.31 \pm$ & 2.34 \\
& 5.69 & 5.35 & 5.43 & 5.02 & \\
\hline $\mathbf{3 5}$ & $84.60 \pm$ & $83.82 \pm$ & $84.92 \pm$ & $84.36 \pm$ & 2.21 \\
& 5.74 & 4.54 & 5.09 & 5.51 & \\
\hline $\mathbf{4 0}$ & $83.94 \pm$ & $83.66 \pm$ & $84.00 \pm$ & $83.62 \pm$ & 2.39 \\
& 5.80 & 5.07 & 5.31 & 5.48 & \\
\hline $\mathbf{4 5}$ & $83.12 \pm$ & $82.82 \pm$ & $84.38 \pm$ & $84.20 \pm$ & 2.54 \\
& 6.17 & 6.00 & 5.42 & 6.24 & \\
\hline
\end{tabular}

Table 3: Sensory and motor characteristics and Apgar Score.

\begin{tabular}{|l|c|c|c|c|c|}
\hline $\begin{array}{l}\text { paramete } \\
\text { r }\end{array}$ & $\mathbf{1 A}$ & $\mathbf{1 B}$ & $\mathbf{2 A}$ & $\mathbf{2 B}$ & $\begin{array}{c}\text { CD } \\
\mathbf{5 \%}\end{array}$ \\
\hline $\begin{array}{l}\text { Onset of } \\
\text { sensory } \\
\text { analgesia }\end{array}$ & $\begin{array}{c}2.54 \pm \\
0.37\end{array}$ & $\begin{array}{c}2.57 \pm \\
0.32\end{array}$ & $\begin{array}{c}2.36 \pm \\
0.33\end{array}$ & $\begin{array}{c}2.64 \pm \\
0.34\end{array}$ & $\begin{array}{c}0.13 \\
7\end{array}$ \\
\hline $\begin{array}{l}\text { Onset of } \\
\text { motor } \\
\text { block }\end{array}$ & $\begin{array}{c}2.97 \pm \\
0.43\end{array}$ & $\begin{array}{c}2.92 \pm \\
0.43\end{array}$ & $\begin{array}{c}3.03 \pm \\
0.312\end{array}$ & $\begin{array}{c}3.03 \pm \\
0.317\end{array}$ & $\begin{array}{c}0.15 \\
0\end{array}$ \\
\hline $\begin{array}{l}\text { Quality of } \\
\text { motor } \\
\text { block }\end{array}$ & $4.00 \pm$ & $4.00 \pm$ & $3.92 \pm$ & $4.00 \pm$ & 0.17 \\
& 0.00 & 0.00 & 0.27 & 0.00 & 0 \\
$\begin{array}{l}\text { Duration } \\
\text { of }\end{array}$ & 182.6 & 180.4 & 154.0 & 156.0 & 4.40 \\
Analgesia & \pm 11.4 & \pm 12.9 & $4 \pm 10$. & $2 \pm 9.3$ & \\
\hline $\begin{array}{l}\text { APGAR } \\
\text { Score }\end{array}$ & $9.14 \pm$ & $9.10 \pm$ & $9.12 \pm$ & $9.10 \pm$ & 0.20 \\
& 0.49 & 0.46 & 0.479 & 0.46 & 1 \\
\hline
\end{tabular}

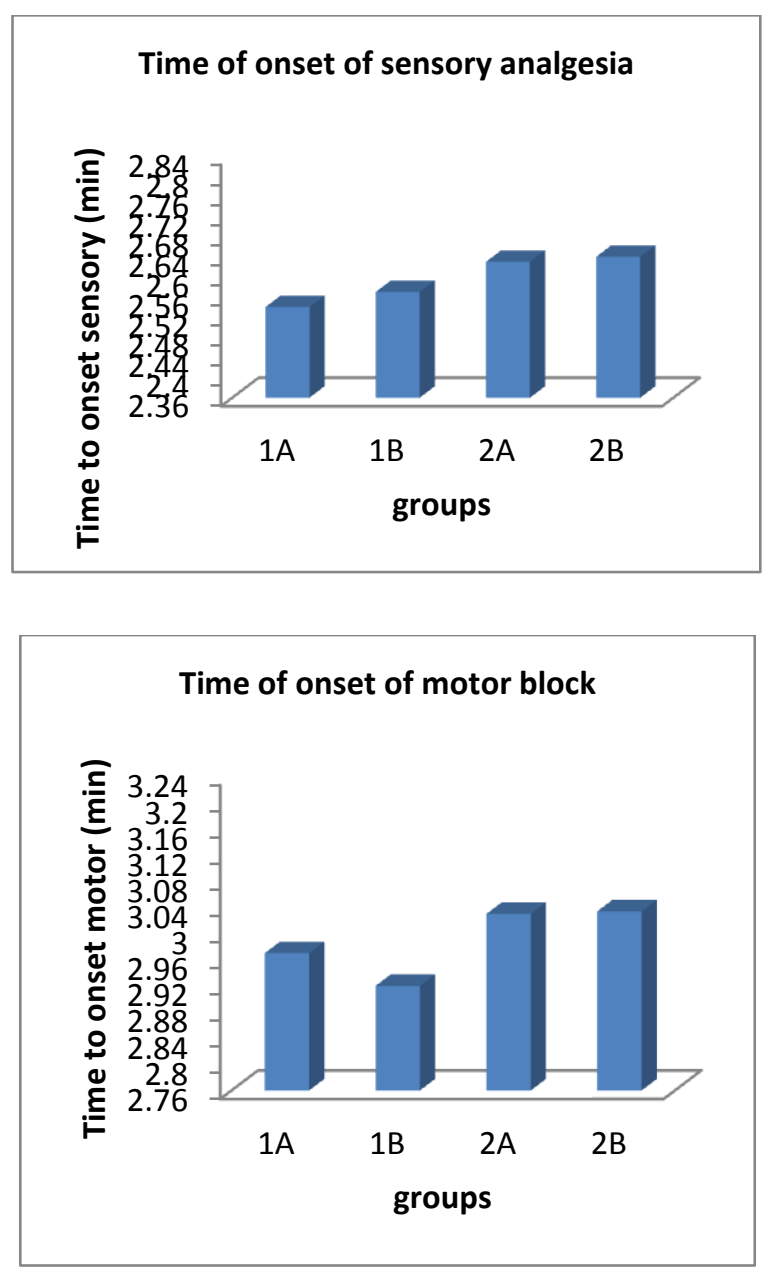


Total duration of analgesia

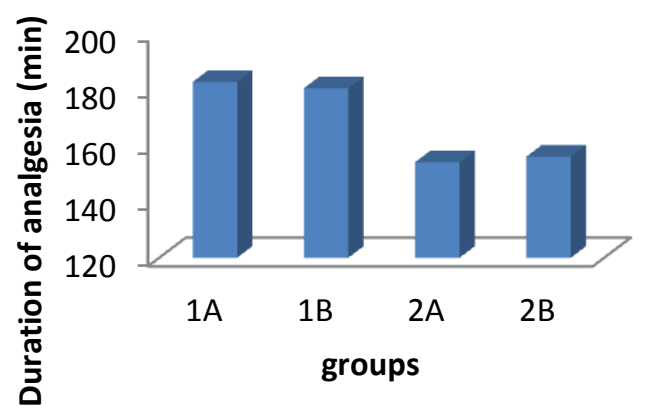

\section{Discussion}

Spinal anaesthesia is the preferred method for elective caesarean section as being simple to perform, economical and producing rapid onset of anaesthesia with complete muscle relaxation. It carries high efficiency, involves less drug doses, minimal neonatal depression and lesser incidences of aspiration pneumonitis. However, it also produces a fixed duration of anaesthesia, lesser control of block height, Postdural puncture headache and hypotension. ${ }^{9}$ Haemodynamic control under spinal anaesthesia is therefore very important Subsequently, hypotension is known to result in maternal morbidity, nausea, vomiting, dizziness and can also have direct influence on neonatal well-being by reducing uteroplacental blood flow. Brief episodes of maternal hypotension have lowered Apgar Score also. Haemodynamic control under spinal anaesthesia is therefore very important.

Various studies have shown various methods to prevent hypotension including use of low dose of anaesthetic drugs, positioning, use of crystalloids or colloids with or without vasopressors. The link between the extent of sympathetic block and the incidence of hypotension has led to numerous attempts at reducing the dose of local anaesthetic and also the addition of opioids due to their synergistic action with local anaesthetic on the sensory block without increasing sympathetic block for caesarean section. ${ }^{10}$

Various authors have used different doses of local anaesthetics and the volume required for spinal anaesthesia in caesarean delivery. Nagata et al., ${ }^{11}$ have reported that $8 \mathrm{mg}$ hyperbaric bupivacaine is preferable to $10 \mathrm{mg}$ in spinal anaesthesia for caesarean section to obtain adequate analgesia and avoid maternal hypotension. In Ben David study, they used $5 \mathrm{mg}$ of isobaric bupivacaine intrathecally with $25 \mathrm{mcg}$ of fentanyl, but there were a number of patients who expressed brief and moderate intraoperative pain which was unacceptable. Subedi et al., ${ }^{12}$ observed that the relatively low dose of bupivacaine use restricted spinal block segments and thus the extent of sympathetic block, thus improving the safety margin of haemodynamic effects seen after spinal anaesthesia. Hence, in our study, we were interested to assess the efficacy of two decreased doses of bupivacaine $(0.5 \%)$ and fentanyl mixture in caesarean section.

The aim of our study was to assess the haemodynamics, onset of action, onset of sensory and motor block and duration of effective analgesia with the combination of fentanyl and low dose hyperbaric bupivacaine. We observed that there was fall in mean blood pressure in all groups with greater fall in blood pressure in group $1 \mathrm{~A}$ and 1B.On comparing group 1A with group 1B the difference was statistically insignificant at different time intervals. On comparing group 1A with group $2 \mathrm{~A}$ and $2 \mathrm{~B}$ the difference was statistically significant at 4 and 6 minutes with CD value $2.67 \%$ and $3.72 \%$ respectively. On comparing group $1 \mathrm{~B}$ with group $2 \mathrm{~A}$ and $2 \mathrm{~B}$ the difference was statistically significant at 4 minutes with $\mathrm{CD}$ value $2.67 \%$. On comparing group $2 \mathrm{~A}$ with group $2 \mathrm{~B}$ the difference was insignificant at different time intervals. So, We observed that mean blood pressure were decreased significantly at 4 and 6 min of spinal anaesthesia in group 1A and $1 \mathrm{~B}$ when compared to $2 \mathrm{~A}$ and $2 \mathrm{~B}$ mostly due to more sympathetic blockade by higher doses. Similar findings were observed by Bogra et al., and also by Seyedhejazi and Madarek. ${ }^{13}$ wherein they studied by using $8 \mathrm{mg}$ of bupivacaine and $10 \mathrm{mcg}$ of fentanyl for spinal anaesthesia in caesarean section. 
Time of onset of sensory analgesia was faster in group 1A and group 1B as compared to group 2A and $2 \mathrm{~B}$ but the difference was statistically insignificant in all four groups with $\mathrm{CD}$ value $0.137 \%$. So, Quality of sensory blockade was good as there was no analgesic supplementation required in both group 1 and 2 even when the uterus was exteriorized, this may be due to addition of fentanyl which blocks the visceral pain, the difference between the groups was insignificant. Similarly time of onset of motor block was faster in group $1 \mathrm{~A}$ and group $1 \mathrm{~B}$ as compared to group $2 \mathrm{~A}$ and $2 \mathrm{~B}$ but the difference was statistically insignificant in all four groups with $\mathrm{CD}$ value $0.150 \%$.So,complete motor blockade was achieved in both groups and the difference was insignificant.

Total duration of analgesia in group 1A was $182.64 \pm 11.45$, group $1 \mathrm{~B}$ was $180.42 \pm 12.93$, group $2 \mathrm{~A}$ was $154.04 \pm 10.56$ and group $2 \mathrm{~B}$ was $156.02 \pm 9.43$. On comparing group 1A with group $1 \mathrm{~B}$ the difference was statistically insignificant. On comparing group $1 \mathrm{~A}$ with group $2 \mathrm{~A}$ and $2 \mathrm{~B}$ the difference was statistically significant with $\mathrm{CD}$ value $4.405 \%$. On comparing group $1 \mathrm{~B}$ with group 2A and 2B the difference was statistically significant with $\mathrm{CD}$ value $4.405 \%$. On comparing group 2A with $2 \mathrm{~B}$ the difference was statistically insignificant. So, the quality of analgesia which was assessed by VAS was excellent in the group 1 , similar observations were made by choi et al., Biswas $^{14}$. The duration of effective analgesia was significantly prolonged in group 1, which also correlates with the study done by Axelsson K.H., H.H.Edstrom et $\mathrm{al}^{15}$. who observed that the duration of analgesia increased with increasing the drug volume. Though duration of analgesia is less in group 2 as compared to group 1 but it provided more stable haemodynamics without compromising required surgical anaesthesia as we have included caesarean section in our study which took maximum upto 40-45 minutes. It provided analgesia for about 155 min which was adequate for the type of surgery chosen.
In our study, none of the newborn babies had 5 min apgar score<7. Similar observations were made by Belzerena, ${ }^{16}$ Biswas, indicating that the dose of fentanyl used may not have a significant effect on the newborn.

None of the patient complained of pruritus and similarly the study by Jashri et al. ${ }^{17}$, observed no incidence of pruritus. Only 4 patients in group 1 complained of nausea and 6 patients complained of nausea and vomiting in group 1 while only 1 patient in group 2 complained of nausea and vomiting may be due to reduction of dose of bupivacaine causing less hypotension in group 2 . Only 2 patients suffered pain during stretching in group $2 \mathrm{~A}$ and 3 in group 2B. Negligible incidences of shivering or respiratory depression was observed in both the groups, which were similar to the findings of Kang et al. ${ }^{18}$

\section{Conclusion}

Based on the above observations we concluded that the group 2 showed better haemodynamic stability with negligible incidence of hypotension with adequate sensory and motor block and adequate duration of total analgesia without compromising surgical anaesthesia with minimal complications to the mother and the foetus. The difference was statistically insignificant between the group with preloading and the group without preloading may be as we have included much lower dose of bupivacaine with fentanyl mixture in our study so we have found no relevance of preloading in avoiding hypotension.

\section{References}

1. Black C, kaye JA, Jick H. Cesaerean delivery in the united kingdom: time trends in the general practice research database. Obstet Gynecol 2005;106:151-5.

2. Denis Snegovskikh, Ferne R.Braveman. Pregnancy associated diseases: ed 2,2012, Stoelting,s Anaesthesia and Co Existing Disease,p563. 
3. Michael A. Frolich. Obstetrics Anaesthesia:ed 5,2013, Morgan \& Mikhail,s Clinical Anaesthesiology, p855.

4. Mc. Crae AF, Wildsmith JA. Prevention and treatment of hypotension during central neural block. Br. J Anaesth 1993; 70:672-80

5. Saravanan S, Kocarev M, Wilson RC, Watkins E, Columb MO, Lyons G. Equivalent dose of ephedrine and phenylephrine in the prevention of post-spinal hypotension in caesarean section. Br J Anaesthesia 2006;96:95-9.

6. Stewart A, Fernando R, Mc Donald S, Hignett $\mathrm{R}$, jones $\mathrm{T}$, Columb $\mathrm{M}$. the dose dependant effect of phenylephrine for elective caesarean delivery under spinal anaesthesia. Anaesth Analg 2010;111:1230-7.

7. Lee A, Ngan Kee WD, Gin T. A quantitative, systematic review of randomized controlled trials of ephedrine vs phenylephrine for the management of hypotension during spinal anaesthesia for caesarean delivery. Anaesth Analog 2002;94:920-6.

8. Cyna AM, Andrew AM, Emmett RS et al: Techniques for preventing hypotension during spinal anaesthesia for caesarean section. Cochrane Database Syst Rev2006;4: CD002251.

9. Caplan RA, Ward RJ, Posner K, Cheney FW. Unexpected cardiac arrest during spinal anaesthesia: A closed claims analysis of predisposing factors. Anaesthesiology 1988;68:5-11.

10. Kaur M, Katyal S, Kathuria S, Singh P. A comparative evaluation of intrathecal bupivacaine alone, sufentanyl or butorphanol in combination with bupivacaine for endoscopic urological surgery. Saudi J Anaesth 2011;5:202-207.

11. Nagata E, Yoshimine $\mathrm{K}$, Minoda $\mathrm{Y}$, Kawaguchi Y, Sakamoto M, Takehara A. Comparison of $8 \mathrm{mg}$ and $10 \mathrm{mg}$ hyperbaric bupivacaine in spinal anaesthesia for caesarean section in Japanese parturients. Masui 2004;53:131-6.
12. Subedi A, Tripathi M, Bhattarai BK, Gupta PK, Pokharal K, Regmi MC. The effect of height and weight adjusted dose of intrathecal hyperbaric bupivacaine for elective caesarean section. JNMA J Nepal Med Assoc 2011;51:16.

13. Seyedhejazi M, Madarek E. Effect of small dose bupivacaine-fentanyl in spinal anaesthesia on haemodynamic nausea and vomiting in caesarean section. Pak J Med Sci 2007;23:747-50.

14. BN Biswas, A Rudra, BK Bose et al Intrathecal bupivacaine with fentanyl improves analgesia during caesarean delivery and in early post operative period. IJA 2002;46(6):469-472.

15. Axelsson K H ,Edström H.Spinal Anaesthesia with Hyperbaric $0.5 \%$ Bupivacaine: Effects of Volume. Acta Anaesthesiologica Scandinavica 1982(26), pages 439-445.

16. Belzarena SD. Clinical effects of intrathecally administered fentanyl in patients undergoing caesarean section. Anaesth Analg 1992;74:653-7.

17. Jaishri bogra, Namita arora, Pratima Srivastava. 2005 "Synergistic effect of intrathecal fentanyl and bupivacaine in spinal anaesthesia for caesarean section":. BMC Anesthesiology.>v.5: 5.

18. Kang FC, Tsai YC, Chang PJ, Chen TY. Subarachnoid fentanyl with diluted small dose bupivacaine for caesarean section delivery. Acta Anaesthesiol Sin 1998;36:207-14. 